\title{
Orta Büyüiklükteki Rotator Manşet Kas Yırtığı Sonrası Artroskopik Omuz Cerrahisi Uygulanan Bireylerde Yenilikçi Bir Yaklaşım: Humeral Baş Depresör Kas Ko-Aktivasyon Eğitimi
}

An Innovative Approach in Individuals Undergoing Arthroscopic Shoulder Surgery After Medium-Sized Rotator Cuff Muscle Tear: Humeral Head Depressor Muscle Co-Activation Training

\author{
Caner Karartı ${ }^{1}$, Anıl Özüdoğru' ${ }^{1}$, Hakkı Çağdaş Basat ${ }^{2}$, İsmail Özsoy ${ }^{3}$ \\ ${ }^{1}$ Krşsehir Ahi Evran Üniversitesi Fizik Tedavi ve Rehabilitasyon Yüksekokulu/ KIRŞEHİR \\ ${ }^{2}$ Kırşehir Ahi Evran Üniversitesi Tip Fakültesi Ortopedi ve Travmatoloji Anabilim Dalı/ KIRŞEHİR \\ ${ }^{3}$ Selçuk Üniversitesi Sağlık Bilimleri Fakültesi Fizyoterapi ve Rehabilitasyon Bölümü/KONYA \\ Yazışma Adresi / Correspondence: \\ Caner Karartı \\ Kırșehir Ahi Evran Üniversitesi Fizik Tedavi ve Rehabilitasyon Yüksekokulu/ KIRȘEHİR \\ T: $+905532235030 \quad$ E-mail : fzt.caner.92@gmail.com \\ Geliș Tarihi / Received : 09.09.2020 Kabul Tarihi / Accepted : 29.11.2020 \\ Orcid : \\ Caner Karartı https://orcid.org/0000-0002-4655-0986 \\ Anıl Özüdoğru https://orcid.org/0000-0002-7507-9863 \\ Hakkı Çağdaș Basat https://orcid.org/0000-0003-3301-2529 \\ İsmail Özsoy https://orcid.org/0000-0001-9048-1116 \\ ( Sakarya Tip Dergisi / Sakarya Med J 2021, 11(1):42-52 ) DOI: 10.31832/ smj.792788
}

\footnotetext{
$\ddot{0 z z}$

Amaç Orta büyüklükte rotator manșet kas yırtığı olan hastalarda konservatif tedaviyle kombine uygulanan humeral baș depresör kas ko-aktivasyon eğitiminin etkilerini değerlendirmektir.

Gereç ve Toplam yirmi dört katılımcı rastgele iki gruba ayrıldı. Kontrol grubundaki bireylere toplam 6 hafta olmak üzere haftada 5 gün konservatif tedavi programı uygulandı.

Yöntem Konservatif tedaviye ek olarak tedavi grubundaki katılımcılar için haftada 5 gün 6 haftalık humeral baş depresör kas ko-aktivasyon eğitimi uygulandı. Katılımcılar hem tedavi öncesi hem de sonrası ağrı ve eklem hareket açıklığı açısından değerlendirildiler.

Bulgular Tedavi grubunda ağrı $(\mathrm{p}=.049 ; \mathrm{p}=.008 ; \mathrm{p}=.009 ; \mathrm{p}=.003)$ ve eklem hareket açıklı̆̆ı skorlarındaki $(\mathrm{p}=.047 ; \mathrm{p}=.007 ; \mathrm{p}=.001)$ iyileșmenin kontrol grubuna göre daha yüksek olduğu bulundu. İç rotasyon hareket açıklı̆̆ açısından iki grup arasında anlamlı fark yoktu $(\mathrm{p}=.499)$.

Sonuç Bu çalıșma, orta büyüklükteki rotator manșet yırtıklarının tedavisinde konservatif tedavi ile birlikte humeral baș depresör kas ko-aktivasyon eğitiminin daha iyi bir seçim olabileceğini düşündürmektedir.

Anahtar Omuz; Rotator Manșet; Rotator Manșet Yaralanmalar

Kelimeler

Abstract

Objective To evaluate the effects of humeral head depressor muscle co-activation training combined with conservative treatment in patients with medium-sized rotator cuff tears.

Materials A total of twenty-four participants were randomly divided into two groups. A conservative treatment program was applied for the participants in the control group for 5 days per week for and methods a total of 6 weeks. In addition to the conservative treatment, humeral head depressor muscle co-activation training was performed for 5 days per week for 6 weeks for the participants in the treatment group. Participants were assessed in terms of pain and range of motion both pre- and post-treatment.

Results It was found that the improvement in pain ( $p=.049 ; p=.008 ; p=.009 ; p=.003)$ and range of motion scores ( $p=.047 ; p=.007 ; p=.001)$ was greater in the treatment group compared to the control group. There was no significant difference between the two groups in terms of internal rotation range of motion ( $p=.499)$.

Conclusion The current study suggests that humeral head depressor muscle co-activation training combined with conservative treatment can be a better choice in the treatment of medium-sized rotator cufftears.

Keywords : Shoulder; Rotator Cuff; Rotator Cuff Injurie
} 


\section{GIIRIŞ}

\%15-\%22 arasında değișen prevalansı ile toplumda en sık görülen muskuloskeletal problemlerden ikincisi olan kronikleşmiş omuz ağrısının önemli sebeplerinden birisi, rotator manşet (RM) kas yırtıklarıdır. ${ }^{1}$ RM yırtıklarının erken dönem tedavisi konservatif olup Level 1 ve 2 oral analjezikleri, non-steroid antiinflamatuar ilaçları, gerekli ise kortikosteroid enjeksiyonlarını ve fizyoterapi yöntemlerini içerir. ${ }^{2}$ Bu tedavi yöntemlerinin uygulanmasına karşın RM yırtığı olan hastalarda, abdüksiyon hareketi sırasında sıklıkla ağrı şiddetinde artma gözlenir. ${ }^{3}$ Ağrıdaki bu artış, kinetik ve kinematik faktörlerin semptomları alevlendirdiğini düşündürmektedir. ${ }^{3}$ Çeşitli radyografi yöntemlerine dayanan çalışmalarda, bu spesifik ağrı şeklinin açığa çıkmasında, abdüksiyon hareketi sırasında yetersiz humeral baş depresyonunun etkili olduğu rapor edilmiștir. ${ }^{4,5} \mathrm{RM}$ yırtığı olan hastaların, humeral baş depresörleri olarak hareket eden omuz kaslarının aktif katkısıyla özellikle abdüksiyon hareketi sırasında subakromiyal dokuların mekanik boşaltılmasından fayda sağlayabilecekleri bildirilmiştir. ${ }^{6}$

Hem sağlıklı kişilerde hem de RM lezyonu hastalarda, deltoid aktivasyonu çoğunlukla kranial yöndeki kuvvet kolunun bir sonucu olarak subakromiyal daralmaya yol açar ve humerusu yukarı doğru çeker. ${ }^{7}$ Sağlıklı bireylerde RM aktivitesi abdüksiyon kuvvetlerini medial yönde oryante ederek ortaya çıkan kuvveti glenoid fossa içine düşürür ve glenohumeral stabilite sağlanır. Semptomatik RM yırtığı olan hastalarda, glenohumeral eklem çevresindeki kas moment dengesi bozulur ve bu da mobilite ve stabilite arasinda bir uyumsuzluğa neden olur: ${ }^{8}$

i) Azalan RM abdüktör kuvvetlerini telafi etmek için abdüksiyon sırasında deltoid kas aktivasyonunda artış olur. ${ }^{8}$ ii) RM disfonksiyonu nedeniyle glenohumeral stabilitede azalma olur. $^{8}$

$\mathrm{Bu}$ mekanizma kombinasyonlarının, hastalarda humerusun aşırı kranializasyonuna (proksimal migrasyon) ve subakromiyal dokuların ağrılı sıkışmasına neden olduğu varsayılmıştır. Glenohumeral stabiliteyi eski haline getirmek için, daha kaudal olarak yönlendirilmiş moment kollarına sahip kol addüktörleri, bu subakromiyal daralmayı azaltmak için hastalarda aktif kol abdüksiyonu sırasında aktive edilmelidir. ${ }^{9} \mathrm{Bu}$ "out-of-phase" addüktör aktivasyonu (ko-aktivasyon) hem model simülasyon çalışmalarında hem de hasta deneylerinde, özellikle medio-kaudal olarak yönlendirilmiş kuvvet vektörlerine sahip teres majör, pektoralis major ve latissimus dorsi kasları için rapor edilmiştir. $^{8,9}$

Subakromiyal daralma ve ağrıyı azaltmak için adduktörlerin birlikte aktivasyonunun çelişkili etkisi, net kol abdüksiyon torkunun azalması ve glenohumeral temas kuvvetinin artmasıdır. ${ }^{9}$ Adduktor ko-aktivasyonu, hastalığın etyolojisi ve hastalıkla başa çıkma mekanizmalarına ilişkin iç görü sağlar ve aynı zamanda tanı ve klinik karar vermede uygulanabilir.9 Semptomatik RM yırtıklarını ayırt etmede, omuz semptomları ve RM patolojileri olan hastalarda etyolojik alt grupların tanımlanması için pratik bir önlem olarak potansiyel değere sahiptir. Ayrıca tedavi etkilerinin objektif olarak değerlendirilmesinde faydalı olabilir. ${ }^{7-9} \mathrm{Su}-$ bakromiyal ağrı sendromu, RM tendinopatisi gibi çeşitli durumlarda etkisi incelenmiş olmasına karşın orta büyüklükte RM yırtığı olan kişilerde humeral baş depresör kas ko-aktivasyon eğitiminin etkisi incelenmemiştir. ${ }^{8,9} \mathrm{Bu}$ bağlamda literatürdeki ilk çalışma olan araştırmamızın amac1, orta büyüklükteki (1-3 cm) RM kas yırtığı sonrası artroskopik rotator manşet onarımı (ARMO) uygulanan bireylerde humeral baş depresör kas ko-aktivasyon eğitiminin etkisini incelemektir.

\section{GEREÇ VE YÖNTEM \\ Çalışma Dizaynı}

$\mathrm{Bu}$ çalışma randomize kontrollü, tek kör çalışma olarak planlandı. CONSORT 2010 Kılavuzuna dayanılarak düzenlenen çalışma protokolü, NCT04154592 (clinicaltrials. gov) ID numarası ile kayıt altına alındı. Çalışmaya katılmayı gönüllü olarak kabul eden ve orta büyüklükte RM kas yırtığı sonrası ARMO uygulanan 24 hasta Faz 1 eği- 
timleri sonrası, blok randomizasyon yöntemi ile 2 gruba ayrıldı. ${ }^{10,11} \mathrm{Bu}$ gruplar sirasiyla tedavi grubu [Konservatif tedaviye ek olarak humeral baş depresör kas ko-aktivasyon eğitimi (KT+Ko-aktivasyon)] ve kontrol grubudur [sadece konservatif tedavi (KT)].

Her iki grubun da konservatif tedavi programı, Amerikan Omuz ve Dirsek Terapistleri Derneğinin ARMO sonrası rehabilitasyon süreçleri hakkında 2016 yılında yayınlamış oldukları rehber eğitim programına göre dizayn edildi. ${ }^{12}$ Ev egzersizi şeklinde düzenlenen post-operatif rutin Faz 1 (0-6. haftalar arası) eğitimlerini tamamlayan ve dahil edilme kriterlerini karşılayan bireylerin Faz 2 (6-12. haftalar) eğitimleri aynı araştırmacı (CK) tarafından supervize olarak yapıldı. Çalışmaya katılmayı kabul eden hastalar, aynı araştırmacı (ÇB) tarafından Faz 1 eğitimleri sonrası (6. hafta tamamlandıktan sonra) ve Faz 2 eğitimleri sonrası (12. hafta tamamlandıktan sonra) gruplara kör olarak değerlendirildiler.

\section{Randomizasyon Tekniği}

Tanı kriterlerini karşılayan, orta büyüklükte RM kas yırtığı sonrası ARMO uygulanan ve rutin Faz 1 eğitimlerini uyum içerisinde ( $\geq \% 80$ uyum oranı) tamamlayan bireyler, çalışma dizaynı için uygun bulundu. Her ardışık hasta, blok randomizasyon yöntemi ile $\mathrm{KT}+\mathrm{Ko}$-aktivasyon veya sadece KT grubuna rastgele atandı. 24 hastayı KT+Ko-aktivasyon ve sadece KT olmak üzere iki farklı gruptan birine rastgele atayabilmek için çeşitli istatistik programlarından yararlanılabilir. ${ }^{10,11}$ Çalışmamızda MedCalc 11.5 .1 paket programı tercih edildi. ${ }^{11}$ MedCalc 11.5.1 paket programında 1 ile 2 arasında rastgele 12 tane sayı üretilerek 1 geldiğinde ilk hasta $\mathrm{KT}+\mathrm{Ko}$-aktivasyon grubuna, ikinci hasta sadece KT grubuna; 2 geldiğinde ise ilk hasta sadece KT grubuna ikinci hasta KT+Ko-aktivasyon grubuna atand. Böylece her blokta iki birey olacak şekilde atama işlemi tamamland1. ${ }^{11}$

\section{Körleme Prosedürü}

Her iki grubun da Faz 2 egzersizleri ile ko-aktivasyon eği- timleri aynı araştırmacı (CK) tarafından uygulandığından çalışmamız, çift kör çalışma düzenine uygun değildi. Hastanın grup numarasının belirlendiği prosedür, çalışmaya dahil olmayan ve çalışma prosedürünü bilmeyen bir sekreter tarafından denetlendi. Daha sonra hasta, değerlendirmeleri yapan hekime (ÇB) yönlendirilerek Faz 2 eğitimleri öncesi gerekli anket ve testler tamamlandı. ÇB, bireylerin hangi grupta olduklarından habersizdi (tek kör). ${ }^{10}$ Tüm bireyler, ilk değerlendirmelerden sonra ilgili eğitimler için fizyoterapiste (CK) yönlendirildiler. Atandıkları grubun özelliklerine göre her birey ev egzersizlerine (Faz 1) ek olarak 6 haftalık tedavi döngüsünün (Faz 2+Katılımcı tedavi grubundaysa ek olarak ko-aktivasyon eğitimi) ardından, ilk değerlendirmeyi yapan ÇB tarafından tekrar değerlendirildi.Supervize eğitimler öncesi ve sonrası değerlendirmelerde aynı prosedürler ve kayıt formları kullanıldı. ${ }^{10}$

\section{Katılımcılar}

Ortopedi ve Travmatoloji Polikliniğine başvuran 24 omuz hastası çalışmaya dahil edildi. Çalışmaya dahil edilme kriterleri; 18-65 yaş arasında birey olmak,Faz 1 eğitimlerini uyum içerisinde tamamlamak, radyolojik yöntemler (MRG) ve klinik testler (devamlılık testleri) sonucu hekim tarafından orta büyüklükte $(1-3 \mathrm{~cm}) \mathrm{RM}$ kas yırtığ 1 tanısı almak, cerrahi yöntem olarak ARMO uygulanmak, bilgilendirilmiş gönüllü onam formu ve ilgili değerlendirme ölçekleri için Türkçe konuşma yetisine sahip olmak, Mini Mental Durum Testinden 24 üzeri skora sahip olmak ve çalışmaya katılmaya gönüllü olmak şeklinde belirlendi..$^{8-10}$ Çalışmaya dahil edilmeme kriterleri; diabetus mellitus varlığı, yağlı dejenerasyon sınıflamasına (Goutallier sınıflaması) göre evre 3 ve daha üstü seviyede olmak,mobilizasyon için kontraendikasyon oluşturabilecek herhangi bir durumun varlığı (hipermobilite, travma, inflamasyon vb.),visual, verbal, kognitif defektler (afazi, unilateral neglect vb.), nörolojik herhangi bir problemin varlığı, servikal disk hernisi varlığı, etkilenen tarafta geçirilmiş omuz fraktürleri, parsiyel RM yırtığı varlığı, etkilenen tarafta geçirilmiş cerrahi öyküsü, adeziv kapsülit varlığı, osteoartrit, romatoid artrit veya sistemik inflamatuar herhangi bir 
problemin varlığı,travmatik omuz instabilitesi (subluksasyon-dislokasyon) öyküsü, tanı öncesi 6 haftalık süre içinde etkilenen taraf için kortikosteroid enjeksiyonu uygulanması şeklinde belirlendi. ${ }^{8-10}$

\section{Etik Kurul İzni}

Çalışmamız, Selçuk Üniversitesi Sağlık Bilimleri Fakültesi Girişimsel Olmayan Klinik Araştırmalar Etik Kurulu tarafından onaylandı (2020-622). Çalışma öncesi tüm bireylerin yazılı ve sözlü onamları alındı ve ayrıca çalışma Helsinki Bildirgesi'ne uyumlu şekilde gerçekleştirildi.

\section{Değerlendirme Yöntemleri}

Tüm bireylerin sosyodemografik özellikleri kaydedildi. Supervize eğitimler öncesi ve sonrası ağrı değerleri görsel analog skala (VAS) ile; eklem hareket açıklık değerleri (ROM) ise universal gonyometre iledeğerlendirildi. ${ }^{13,14}$

\section{Görsel Analog Skala (VAS)}

Katılımcıların sırasıyla istirahat, aktivite, Neer Testi ve Kennedy-Hawkins testi sırasında omuz ekleminde hissettikleri ağrı şiddeti, VAS ile değerlendirildi. VAS, herhangi bir dilinin olmaması nedeniyle kullanımı kolay olan bir skaladır ve kliniklerde sıklıkla uygulanmaktadır. Bireylerden test sırasında hissettikleri ağrıyı $10 \mathrm{~cm}$ ' lik ölçekte " 0 " (ağrı yok) ve "10” (dayanılmaz ağrı) olacak şekilde tariflemeleri istendi. ${ }^{13}$

\section{Eklem Hareket Açıklık Değerleri (ROM)}

Çalışmaya katılan tüm bireylerin fleksiyon, abduksiyon, internal rotasyon ve eksternal rotasyon olmak üzere omuz ROM'ları universal gonyometre ile değerlendirildi. Gonyometrik ölçüm, klinikte ROM değerlendirilmesinde sıklıkla kullanılan bir yöntemdir. ${ }^{14}$ Eklem hareket sınırının değerlendirilmesine ek olarak fonksiyonel kapasiteyi saptamak, tedavi programına karar vermek ve tedavinin etkinliğini belirlemek amacıyla da kullanılmaktadır. ${ }^{14}$

Gonyometre ölçümleri, bireyler sırt üstü yatış pozisyonunda iken yapıldı. ${ }^{14}$ Fleksiyon hareketinin ROM değerlendir- mesinde pivot nokta humerusun büyük tüberkülü, hareketli kol ise humerusun lateral kondiline doğru, humerus orta çizgisine paralel olacak şekilde yerleştirildi. Abduksiyon hareketi için, pivot nokta akromiyona, hareketli kol ise humerusun anterior orta çizgisine paralel olacak şekilde ölçüm yapıldı. Eksternal ve internal rotasyon için ise, omuz $90^{\circ}$ abduksiyon ve dirsek $90^{\circ}$ fleksiyonda bireylerin üst ekstremitesi pozisyonlandı. Sabit kol yere paralel iken hareketli kol 3. metakarpofalangeal eklemin uzun eksenini takip etti. ${ }^{14}$ Tüm ölçümlerde AROM değerlendirildi.

\section{Tedavi Yöntemleri}

\section{Konservatif Tedavi Yöntemleri}

Her iki grubun da konservatif tedavi programı, Amerikan Omuz ve Dirsek Terapistleri Derneğínin ARMO sonrası rehabilitasyon süreçleri hakkında 2016 yılında yayınlamış oldukları rehber eğitim programına göre dizayn edildi. ${ }^{12}$

\section{Faz 1 Eğitimi (0-6. haftalar)}

Literatürde ARMO sonrası çoğunlukla immobilizasyon dönemi olarak düşünülen dönemdir. ${ }^{12}$ Çalışmamızda da ev egzersizi ve immobilizasyon dönemi olarak planlanan Faz 1 dönemi, hasta eğitimini, modaliteleri, pasif ROM' $\mathrm{u}$ ve immobilizasyon yöntemlerini içeren dönem olarak planlandı. Bu dönem klinik çalışmaya bağlı olmaksızın ARMO sonrası benzer eğitimleri içerdiğinden bu dönemi tamamlayan 24 katılımcı çalışmaya ve randomizasyona dahil edildi.Hekim rutin olarak bu dönemde hastalardan eğitime uyum süreçlerini ve kullanmak zorunda kaldıkları medikal yöntemleri kaydetmeleri için günlük tutmalarını istedi. Günde toplam 1 saat egzersiz ve temizlik işlerine ayrıldı. Geri kalan 23 saat immobilizasyon süresi olarak düşünüldü. Bu faz sırasındaki uygulamalar sırasıyla şunlardir:

i) Hasta eğitiminde patolojinin ve tedavi prosedürünün hasta tarafından kavranılması amacıyla RM kaslarının yeri ve görevleri anatomik görseller vasitasıyla hasta ve ailesine anlatıldı. Re-rüptür oranının sıklığı nedeniyle hekim-fizyoterapist-hasta arasında sıkı bir kooperasyon gerektiği, her bir fazda alınacak koruyucu önlemler aktarıldı. Breys 
kullanım şekli, temizlik işlerinin nasıl yapılacağı konusunda bilgilendirme yapıldı. ${ }^{12}$

ii) Özellikle ilk 72 saatlik dönemde opioid kullanımı ve post-operatif ağrıyı azalttığı bilindiğinden hastalardan omuz bölgelerine iki saate bir 20 dakika soğuk uygulamaları istendi. ${ }^{12}$

iii) Kasların EMG aktivitelerini \%15' in altında tutacak egzersizler seçildi. Tanımlanan her egzersiz, bir set 10 tekrar olmak üzere 3 set şeklinde yapıldı. Setler arası 1 dakika, farklı egzersizler arasında ise 3 dakika dinlenme süresi uygulandı. Faz 1 dönemi olduğu için korumanın öncelikli olduğu ve tüm egzersizlerin ağrı sınırında yapılması gerektiği belirtildi. ${ }^{12}$ Uygulanan egzersizler sırasıyla; pendulum egzersizleri, masa kenarında pasif fleksiyon ve abduksiyon germe, ayakta maksimum $120^{\circ}$ ye kadar (tolere edemeyenlerde $90^{\circ}$ ) pasif öne elevasyon, maksimum $30^{\circ}$ ye kadar $20^{\circ}$ abduksiyonda pasif eksternal rotasyon, self yardımlı supin pozisyonda öne elevasyon, wand ile yardımlı eksternal ve internal rotasyon ve aktif servikal hareketlerin yapılmasidir. ${ }^{12}$

Çalışmamızda immobilizasyon yöntemi olarak "Velpeau bandajı" seçildi. Hastaların 23 saat boyunca bandajı kullanmaları istendi. ${ }^{15}$

\section{Faz 2 Eğitimi (6-12. haftalar)}

Tüm hastalar Faz 1 eğitimlerini ev ortamında tamamladıktan sonra dahil edilme kriterlerini karşılamaları durumunda supervize Faz 2 eğitimleri için Fizyoterapi ve Rehabitasyon kliniklerine başvurdular. $\mathrm{Bu}$ faz başlamadan önce Velpeau bandajı tekrar kullanılmamak üzere çıkarıldı. Fizyoterapist (CK) tarafından Faz 2 eğitiminin uygulanması sırasında kasların EMG aktivitelerini \%29' un altında tutacak egzersizler seçildi. ${ }^{12}$ Haftada 5 gün her seans yaklaşık 90 dakika olacak şekilde planlama yapıldı. Tanımlanan her egzersiz, bir set 10 tekrar olmak üzere 3 set şeklinde yapıldı. Setler arası 1 dakika, farklı egzersizler arasında ise 3 dakika dinlenme süresi uygulandı. Ev ortamında omuz bölgesine iki saate bir 20 dakika soğuk uygulamasına devam edildi. Belirtilen egzersizler ev ortamında da hastalara ödev şeklinde verildi ve günlük vasıtasıyla tedaviye uyum gözlemlendi. ${ }^{12}$

$\mathrm{Bu}$ faz sırasında uygulanan eğitimler sırasıyla; omuz bölgesine 20 dakika soğuk uygulama, 20 dakika Konvansiyonel TENS (60-120 Hz. arası) uygulamas1, deltoid ve biseps kasları için yumuşak doku masajı (3 dakika), skapula ve glenohumeral eklem mobilizasyonları (Grade A-B), ayakta duruşta duvarda havlu kaydırma ve duvarda toz alma egzersizi, wand ile yardımlı $120^{\circ}$ ye kadar bilateral omuz elevasyonu, 9. haftadan sonra artan abduksiyon açılarında eksternal rotasyon, abduksiyonda internal rotasyon, horizontal adduksiyon ve fonksiyonel internal rotasyon (el dorsumu lumbalde ve daha yukarıda) egzersizleri, VAS' a göre aktivite sırasında 2 birim ve altında ağrıya ulaşıldığında sırt üstü ve yan yatış pozisyonlarında ve RM/deltoid dengesini sağlamak için dirsek fleksiyonda kısa kaldıraç kolunda kuvvetlendirme eğitimleri, parmak merdiveni egzersizleri, 0.5 kg ile başparmak yukarıda "Full Can" pozisyonunda kuvvetlendirme eğitimi, statik quadripedal pozisyonunda kapalı kinetik zincir eğitimleri, periskapular kasların, deltoidin ve trapezin izometrik egzersizleri, posterior kapsül germe, aktif elevasyon derecesi arttıkça göğüs seviyesinde deltoid, RM ve skapular kasların aktivasyon eğitimleri için dört anahtar egzersiz uygulaması: ${ }^{12}$

i) (Maksimum kırmızı renk elastik bant yardımı ile eksternal rotasyon (infraspinatus ve teres minör),

ii) İnternal rotasyon (subskapularis),

iii) Deltoid ve periskapular kas eğitimi,

iv) Kısa kol kaldıraçta öne elevasyon ya da öne uzanma (anterior deltoid ve supraspinatus).

\section{Humeral Baş Depresör Kas Ko-Aktivasyon Eğitimi}

Tedavi grubundaki bireylere, 6 haftalık Faz 2 (6-12. haftalar) eğitimlerine ek olarak Faz 2 eğitiminin başladığı 6 . haftadan itibaren "Humeral Baş Depresör Kas Ko-aktivasyon Eğitimi” senkronize şekilde uygulandı. Ko-aktivasyon eğitimi için standart bir test ve eğitim protokolü kullanıld1. ${ }^{9}$ Abdüksiyon hareketi sırasında skapulaya göre humerusun kraniokaudal pozisyonuna doğrudan etki eden 
kasların aktivasyon modelleri temel alınarak bu modellere uygun eğitim verildi. ${ }^{6}$ Humeral baş depresör kaslar, güçlüden zayıfa doğru sırasıyla teres majör, latissimus dorsi ve pektoralis majördür. Humeral baş depresyonuna katkıda bulunan diğer kasların (infraspinatus ve subskapularis kaslarının alt lifleri) EMG Biofeedback cihazı ile eğitilmesi invaziv iğne elektrotlar gerektirdiğinden, eğitim programı teres majör, latissimus dorsi ve pektoralis major kaslarıyla sinırlandırıldı. ${ }^{2,6}$

Ko-aktivasyon eğitimi için nöromusküler temelli bir eğitim aracı olan EMG Biofeedback [Chattanooga Group Inc., Chattanooga, TN] (EMG-BF) cihazından faydalanıld. EMG-BF, yüzeyel elektrotlar vasıtasıyla kas içi myoelektriksel sinyalleri görsel ve işitsel değerlere dönüştürerek kasın re-edukasyonunu sağlayan bir cihazdır. ${ }^{16}$ Kas kontraksiyonu sırasında sarkolemmanın depolarizasyonu ile meydana gelen Motor Ünite Aksiyon Potansiyeli (MÜAP), EMG-BF cihazının göstergesinde mikrovolt cinsinden gösterilir. ${ }^{16}$

Katılımcıda başarma algısının ve odaklanmanın artırılmas1 amacıyla, ko-aktivasyon eğitimine başlanmadan önce humeral baş depresör kasların anatomisi görseller yardımı ile hastalara tariflendi. EMG-BF uygulaması için hastalar, sessiz ve sakin bir tedavi kliniğine alınarak dış ortam ile ilişkileri kesildi. Uygulama yapılmadan önce cilt alkollü pamuk ile temizlendi. Uygulamada, Stimrodes ${ }^{\circledast} 3.2 \mathrm{~cm}$ çapında elektrotlar kullanıldı. ${ }^{17}$ Teres majör için, aktif elektrotlardan biri skapulanın inferior açısının 1 santimetre superolateraline, diğeri humerusun küçük tüberkülü üzerine yerleştirildi. Latissimus dorsi için aktif elektrotlardan biri, skapulanın alt açısının bir santimetre altındaki kas karnına, diğeri iliakkristanın 1 santimetre üzerine yerleştirildi. Pektoralis major için ise, elektrotlardan biri sternal parça venter kısmının 2/3 lateral bölümüne, diğeri ise üçüncü kostanın kostokondral eklemi üzerine yerleştirildi. ${ }^{10}$

Hastalar cihazı rahatlıkla görebilecek konumda ve oturur şekilde pozisyonlandılar. Çalışma hedefi "Hedefi belir- le" butonu ile belirlenmeden önce katılımcilar tarafından humeral baş depresör kasların en az üç (beş adede kadar) tekrar Maksimum İzometrik Kasılması (MVIC) gerçekleştirildi. Bu alışma tekrarları arasında 1 dakika dinlenme periyodu uygulandı. En yüksek EMG-BF mikrovolt değeri, çalışma hedefini belirlemede gerekli skor olarak seçildi.

Tüm bireylerin MVIC değerlerinin hesaplanmasında, skapular düzlemde $45^{\circ}$ lik elevasyon hareketi esas alındı. ${ }^{16,17}$ Teres majör ve latissimus dorsi MVIC’ leri için hastalardan $45^{\circ}$ lik elevasyon hareketi sırasında kola iç rotasyon, adduksiyon ve ekstansiyon yaptırmaya odaklanarak omzu arkaya doğru çekmeye çalışmaları istendi. Pektoralis majör MVIC için de hastaların fleksiyon, iç rotasyon ve adduksiyon hareketine odaklanarak omuzu öne ve içeri doğru çekmeye çalışmaları istendi. Görsel geri bildirimler için cihazın ekranında yer alan kesikli çizgilerden ve işitsel geri bildirim için sinyal sesinden yararlanıld..$^{16,17}$

Yapılan çalışmada, humeral baş depresör kaslarda ko-aktivasyon artışı amaçlandığı için alışma tekrarları sırasında belirlenen hedef MVIC, \%50 artırılarak yeni hedef belirlendi. Hastaya, ilgili hareketleri yaparken kesikli çizgilerin, hedef çizginin altında kalmaması gerektiği anlatıldı. ${ }^{16,17}$ Her hastaya ilk gün bu 1 saatlik alışma ve odaklanma eğitimi verildikten sonra Faz 2 eğitimlerine geçildi. Faz 2 eğitimlerine geçmek için her bir hastanın ko-aktivasyonu doğru bir şekilde uygulandığından emin olundu. Faz 2 eğitimleri sırasında fizyoterapist ile her seans öncesi katılımcıların ko-aktivasyonu gerçekleştirebilme kapasiteleri değerlendirildi. Gerekirse, egzersizler doğru yapılana kadar EMG-BF cihazı kullanılarak fizyoterapist ile ek denemeler yapıldı. Haftalık telefon görüşmesi ile katılımcılara ko-aktivasyon eğitimi için odaklanmayı ev ortamında da çalışmaları gerektiği ve gereken prosedür hatırlatıldı. Ko-aktivasyon eğitiminin ev ödevi bölümüne hastaların uyumunu saptamak için günlük tutturuldu. ${ }^{16,17}$

KT+Ko-aktivasyon grubundaki bireylerden, Faz 2 eğitiminin glenohumeral egzersizlerinden önce EMG-BF cihaz1- 
nın görsel ve işitsel uyarıları ile teres majör, latissimus dorsi, pektoralis majör kaslarını yukarıda bahsedilen şekilde istemli olarak aktive etmeleri istendi. Tüm glenohumeral egzersizlerin, humeral baş depresör kasların ko-aktivasyonu bozulmadan yapılması gerektiği ifade edildi ve cihaz yardımıyla performans kontrol edildi. Öte yandan, sadece KT grubundaki bireylerin teres majör, latissimus dorsi ve pektoralis majör kaslarını hareketler sırasında aktive etmemesi gerektiğinden haftalık olarak 1 kereliğine bu hastaların sadece EMG-BF MVIC değerleri ölçülerek MVIC' in \% $15^{\prime}$ in altında olduğundan emin olundu. ${ }^{16,17}$

\section{Örneklem Büyüklüğ̈̈i}

Orta büyüklükteki RM kas yırtığı sonrası ARMO uygulanan bireylerde humeral baş depresör kas ko-aktivasyon eğitiminin etkisinin incelendiği herhangi bir çalışma literatürde mevcut değildir. Bu nedenle çalışmamızda örneklem büyüklügüünün saptanmasında Overbeek ve ark.' nın çalışma sonuçları referans alındı. ${ }^{18}$ Overbeek ve ark. humeral baş depresör kasların artmış ko-kontraksiyonunun, subakromiyal ağrı sendromundaki klinik seyir ile ilişkisini incelemişlerdir. Bu çalışma sonuçlarına göre geniş etki büyüklüğü hesaplandı. $G^{\star}$ Power Software (Version 3.1.9.2, DüsseldorfUniversity, Düsseldorf, Germany) ile yapılan analizde, 0.8'lik etki büyüklüğünde, \% 95 güven aralığında ve \% 80 güçte 2 grupta mikst dizaynda tekrarlı ölçümler ANOVA testi yapabilmek için her gruba 12 birey olmak üzere toplam 24 bireyin dahil edilmesi gerektiği saptandı.

\section{İstatistiksel Analiz}

Verilerin istatistiksel analizinde The IBM $^{\bowtie}$ SPSS $^{\circledast}$ Statisticsfor Windows software (ver. 22.0; IBM Corp., NY, USA) yazılımı kullanıldı. Tüm sonuçlar için tedaviye niyet prensibi ve protokol başına analizler gerçekleştirildi. Sayısal değişkenlerin normal dağılıp dağılmadıkları, görsel (histogramlar, olasılık grafikleri) ve analitik yöntemler (Kolmogorov-Simirnov/Shapiro-Wilk testi) kullanılarak belirlendi. Normal dağılım gösteren veriler için parametrik analiz yöntemleri kullanıldı. Tanımlayıcı istatistikler sürekli sayısal değişkenler için minimum-maksimum ve ortalama \pm standart sapma (ortalama \pm SS) olarak; kategorik değişkenler için oran (\%) olarak ifade edildi. Gruplar açısından temel parametreler bağımsız örneklem t testi (yaş, vücut kütle indeksi) ve $\chi^{2}$ testi (cinsiyet dağılımı, dominant taraf, etkilenen taraf, ev egzersizleri sirasinda günlük tutma vasıtasıyla tedaviye uyum) kullanılarak karşılaştırıldı. Tedavi öncesi ve sonrası grup içi farklılıkların saptanmasında eşleştirilmiş örneklem t testi kullanıldı. Mikst dizaynda iki yönlü tekrarlı ölçümler varyans analizi (ANOVA) [bağımsız faktör grup: KT+Ko-aktivasyon grubu ve sadece KT grubu; tekrarlanan faktör zaman: tedavi öncesi ve tedavi sonrası] zamana bağlı değişim ve grupxzaman etkileşimleri açısından skorları karşılaştırmak için kullanıldı. Etki büyüklükleri (f) "partial eta squared” olarak ifade edildi [ $f=0.10$ (küçük etki büyüklüğü), $f=0.25$ (orta etki büyüklüğü) ve $\mathrm{f}=0.40$ (geniş etki büyüklüğü)]. Grup, zaman veya grupxzaman etkileşimi için saptanan önemli farklılıklarda Bonferroni post-hoc testi kullanıldı. Tüm analizler için istatistiksel anlamlılık değeri $\mathrm{p}<.05$ olarak ayarlandı.

\section{BULGULAR}

Orta büyüklükte RM kas yırtığı sonrası ARMO uygulanan 24 birey çalışmaya dahil edildi. Katılımcıların tanımlayıcı istatistikleri Tablo 1' de gösterildi. İncelenen gruplar temel parametreler açısından benzerdi p $>.05$ ve bu durum grupların homojen dağıldığını ortaya koydu. Toplam 42 günlük ko-aktivasyon eğitiminin ev ödevi bölümüne uyum oranının ise $\mathrm{KT}+\mathrm{Ko}$-aktivasyon grubu için \%90.47 olduğu bulundu.

\section{Ağrı Değişkeni Açısından Gruplar Arası Karşılaştırma}

Analizler, her iki tedavi programının da faydalı etkiler sağladığını gösterdi $(\mathrm{p}<.05)$. Dört farklı durum üzerinde gerçekleştirilen ANOVA, hem grup etkisi $(\mathrm{p}<.001)$ hem de tedavi etkisi $(\mathrm{p}<.001)$ ortaya çıkardı. Grup ve tedavi arasında da istatistiksel olarak anlamlı bir etkileşim saptandı ( $\mathrm{p}<.05)$. Grup içi değerlendirmelerde tüm ölçümler için her iki tedavinin de etkili olduğu saptandı $(\mathrm{p}<.001)$. Tüm pozisyonlar açısından $\mathrm{KT}+\mathrm{Ko}$-aktivasyon grubundaki iyi- 
Sakarya Tip Dergisi 2021;11(1):42-52

KARARTI ve Ark., Humeral Baș Depresör Kas Ko-Aktivasyon Eğitimi

\begin{tabular}{|c|c|c|c|}
\hline & KT+Ko-aktivasyon & Sadece KT & $\mathbf{p}$ \\
\hline Kadın (\%) & $11(91.7)$ & $11(91.7)$ & $1.0^{\mathrm{a}}$ \\
\hline Yaş (SS; min-max) & $46.58(7.47 ; 36-61)$ & $50.25(7.37 ; 36-62)$ & $.23^{\mathrm{b}}$ \\
\hline VKİ (SS; min-max) & $26.4(4.48 ; 17.9-39.1)$ & $25.1(4.12 ; 18.4-36.5)$ & $.21^{\mathrm{b}}$ \\
\hline Dominant taraf sağ (\%) & $12(100.00)$ & $12(100.00)$ & $1.0^{\mathrm{a}}$ \\
\hline Etkilenmiş taraf sağ (\%) & $12(100.00)$ & $12(100.00)$ & $1.0^{\mathrm{a}}$ \\
\hline Faz 1 egzersizlerine uyum (\%) & $36 / 42$ gün $(85.71)$ & 42/42 gün (100.00) & $.04^{\mathrm{a} *}$ \\
\hline Faz 2 egzersizlerine uyum (\%) & $34 / 42$ gün (80.95) & 41/42 gün (97.61) & $.02^{\mathrm{a} *}$ \\
\hline Ko-aktivasyon eğitimine uyum (\%) & - & 38/42 gün (90.47) & - \\
\hline \multicolumn{3}{|c|}{$\begin{array}{l}\text { VKİ: Vücut kütle indeksi; SS: Standart sapma; a } \chi 2 \text { testi; b Bağımsız örneklem t testi; \%: Yüzde; min-max: Minimum-mak- } \\
\text { simum; KT+Ko-aktivasyon: KT+Ko-aktivasyon: Konservatif tedaviye ek olarak humeral baş depresör kas ko-aktivasyon } \\
\text { eğitimi; KT: Sadece konservatif tedavi. }\end{array}$} & \\
\hline
\end{tabular}

Tablo 2. Ağrı Değişkeni Açısından Tedavi Öncesi ve Sonrası Gruplar Arası Karşılaştırma

\begin{tabular}{|l|c|c|c|c|c|c|c|c|}
\hline & \multicolumn{3}{|c|}{ Sadece KT grubu } & \multicolumn{2}{c|}{ KT+Ko-aktivasyon Grubu } & \multicolumn{2}{c|}{$\mathbf{p}^{2}$ değeri } \\
\hline & Önce & Sonra & $\mathrm{p}^{1}$ değeri & Önce & Sonra & $\mathrm{p}^{1}$ değeri & Zaman & Grup $\times$ Zaman \\
\hline İstirahat & $5.08 \pm 1.37$ & $3.28 \pm 1.52$ & $<.001$ & $5.66 \pm 1.15$ & $2.45 \pm 0.44$ & $<.001$ & $<.001(0.912)$ & $.049(0.311)^{*}$ \\
\hline Aktivite & $7.16 \pm 1.33$ & $3.96 \pm 0.82$ & $<.001$ & $7.50 \pm 1.00$ & $2.48 \pm 0.58$ & $<.001$ & $<.001(0.923)$ & $.008(0.493)^{*}$ \\
\hline Neer & $7.33 \pm 1.43$ & $4.49 \pm 0.99$ & $<.001$ & $7.16 \pm 1.19$ & $2.88 \pm 0.86$ & $<.001$ & $<.001(0.922)$ & $.009(0.488)^{*}$ \\
\hline Kennedy-Hawkins & $8.33 \pm 0.88$ & $5.78 \pm 0.87$ & $<.001$ & $8.16 \pm 0.57$ & $3.87 \pm 0.48$ & $<.001$ & $<.001(0.989)$ & $.003(0.542)^{*}$ \\
\hline
\end{tabular}

VAS: Görsel Analog Skalası; $\mathrm{p}^{1}$ : eşleştirilmiş örneklem $\mathrm{t}$ testi; $\mathrm{p}^{2}$ : Mikst dizaynda iki yönlü tekrarlı ölçümler varyans analizi (ANO-

VA). Değerler ortalama \pm standart sapma şeklinde ifade edildi. Parantez içindeki veriler etki büyüklüklerini tarifler; KT+Ko-aktivasyon:

KT+Ko-aktivasyon: Konservatif tedaviye ek olarak humeral baş depresör kas ko-aktivasyon eğitimi; KT: Sadece konservatif tedavi.

leşmenin daha yüksek olduğu saptandı ( $<$ <.05, Tablo 2).

\section{Eklem Hareket Açıklık Değerleri Açısından Gruplar}

\section{Arası Karşılaștırma}

Uygulanan her iki tedavinin de ROM değerleri açısından faydalı sonuçlara yol açtığı saptandı $(\mathrm{p}<.05)$. ANOVA, internal rotasyon hareketi dışında diğer 3 farklı ROM ölçümünde hem grup etkisi $(\mathrm{p}<.001)$ hem de tedavi etkisi $(\mathrm{p}<.001)$ ortaya çıkardı. Grup ve tedavi arasında da istatistiksel olarak anlamlı bir etkileşim bulundu $(\mathrm{p}<.05)$. Grup içi değerlendirmelerde tüm ölçümler için her iki tedavinin de etkili olduğu saptandı ( $\mathrm{p}<.001)$. Fleksiyon, abduksiyon ve eksternal rotasyon hareketlerindeki iyileşme açısından KT+Ko-aktivasyon grubunun üstün olduğu görüldü $(\mathrm{p}<.05$, Tablo 3$)$.

Tablo 3. Eklem Hareket Açıklık Değerleri Açısından Tedavi Öncesi ve Sonrası Gruplar Arası Karşılaştırma

\begin{tabular}{|l|c|c|c|c|c|c|c|c|}
\hline \multirow{2}{*}{ ROM } & \multicolumn{3}{|c|}{ Sadece KT grubu } & \multicolumn{2}{c|}{ KT+Ko-aktivasyon Grubu } & \multicolumn{2}{c|}{$\mathbf{p}^{2}$ değeri } \\
\cline { 2 - 9 } & Önce & Sonra & $\mathrm{p}^{1}$ değeri & Önce & Sonra & $\mathrm{p}^{1}$ değeri & Zaman & Grup $\times$ Zaman \\
\hline Fleksiyon & $98.66 \pm 12.40$ & $123.23 \pm 8.75$ & $<.001$ & $97.25 \pm 8.51$ & $137.42 \pm 5.12$ & $<.001$ & $<.001(0.951)$ & $.047(0.343)^{*}$ \\
\hline Abduksiyon & $49.66 \pm 15.82$ & $112.21 \pm 8.9$ & $<.001$ & $47.91 \pm 14.20$ & $129.84 \pm 7.58$ & $<.001$ & $<.001(0.942)$ & $.007(0.502)^{*}$ \\
\hline $\begin{array}{l}\text { Eksternal } \\
\text { Rotasyon }\end{array}$ & $5.66 \pm 4.84$ & $26.13 \pm 6.44$ & $<.001$ & $6.16 \pm 4.62$ & $32.48 \pm 8.78$ & $<.001$ & $<.001(0.925)$ & $<.001(0.798)^{*}$ \\
\hline $\begin{array}{l}\text { İnternal } \\
\text { Rotasyon }\end{array}$ & $18.83 \pm 9.00$ & $43.25 \pm 4.88$ & $<.001$ & $17.75 \pm 8.13$ & $42.65 \pm 6.14$ & $<.001$ & $.896(0.004)$ & $.499(0.038)$ \\
\hline
\end{tabular}

ROM: Eklem Hareket Açıklığı; $\mathrm{p}^{1}$ : eşleştirilmiş örneklem t testi; $\mathrm{p}^{2}$ : Mikst dizaynda iki yönlü tekrarlı ölçümler varyans analizi (ANOVA). Değerler ortalama \pm standart sapma şeklinde ifade edildi. Parantez içindeki veriler etki büyüklüklerini tarifler; KT+Ko-aktivasyon: KT+Ko-aktivasyon: Konservatif tedaviye ek olarak humeral baş depresör kas ko-aktivasyon eğitimi; KT: Sadece konservatif tedavi. 


\section{TARTIŞMA}

$\mathrm{Bu}$ çalışma, orta büyüklükteki RM kas yırtığı sonrası ARMO uygulanan bireylerde humeral baş depresör kas ko-aktivasyon eğitiminin etkisinin incelenmesi amaciyla planlandı. Çalışma sonuçlarına göre, konservatif tedavi programına, ko-aktivasyon eğitiminin eklenmesinin ağrı ve eklem hareket açıklığı açısından olumlu etkisi vardır.

Semptomatik RM lezyonu olan hastalarda, semptomların daha da kötüleşmesine yol açan predispozan faktörlerden biri deltoid kastaki aktivasyon artışıdır.7 Glenohumeral eklem çevresindeki kas moment dengesi anomalilerinden dolayı ortaya çıkan mobilite-stabilite uyumsuzluğu, humeral başın aşırı kranializasyonuna yol açarak akromiyohumeral mesafeyi daraltır ve fonksiyonel yetersizlikleri artırır. ${ }^{8,9}$ Semptomların hafifletilebilmesi için çeşitli yöntemler aranmakta olup, son zamanlarda etkisinin incelenmesi konusunda çalışmalara ihtiyaç olduğu vurgulanan eğitimlerden birisi, humeral baş depresör kas ko-aktivasyon eğitimidir. ${ }^{89}$ Biyomekaniksel analiz çalışmalarında teres majör, pektoralis major ve latissimus dorsi kaslarının glenohumeral egzersizler sırasında ko-aktivasyon sağlaması gerektiği ancak bu şekilde medio-kaudal moment kolla-

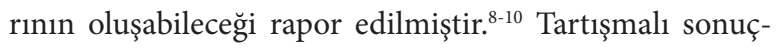
lar olsa da medio-kaudal moment kollarına sahip kol kol addüktörlerinin ko-aktivasyonu ile glenohumeral mobilite ve stabilitenin restorasyonunun sağlanabileceği düşüncesi önem kazanmaktadır.9 Bu düşünce, çalışmamızın önemli çıkış noktalarından birisidir. Çalışmamız orta büyüklükteki RM kas yırtığı sonrası ARMO uygulanan bireylerde humeral baş depresör kas ko-aktivasyon eğitiminin etkisinin incelendiği ilk çalışma olma özelliği taşıdığından sonuçlarımız EMG çalışmaları ile desteklenmiştir.

Witte ve arkadaşlarının EMG’ ye dayalı çalışmaları, humeral baş depresör kas ko-aktivasyon eğitiminin gerekliliği konusundaki sonuçlarımızı destekler niteliktedir. ${ }^{9}$ Yirmi sağlıklı ve 20 tam kat RM yırtığı olan toplam 40 katılımcı ile yapmış oldukları çalışmalarında, EMG kaydı sırasında izometrik abduksiyon ve adduksiyon hareketlerini incelemişlerdir. Abduksiyon ve adduksiyon EMG sonuçları "Aktivasyon Oranı $(-1 \leq \mathrm{AO} \leq 1)$ " olarak ifade edilmiş olup daha küçük oranlar daha yüksek ko-aktivasyonu tariflemektedir. Tam kat yırtığı olan bireylerin kompansasyon mekanizması olarak abduksiyon hareketi sırasında daha yüksek adduktor kas ko-aktivasyonu gösterdiğini rapor etmişlerdir. ${ }^{9}$ AO' lar teres majör kası için 0.3; latissimusdorsi kası için ise 0.5 olarak bulunmuştur. Eğitim olarak verilmesinin yanı sıra bu AO' ların semptomatik RM yırtığı olan kişilerin sağlıklılardan ayırt edilmesinde indikatör olarak kullanılabileceğini ifade etmişlerdir. ${ }^{9}$

Witte ve arkadaşları, RM disfonksiyonlu hastalarda abduksiyon hareketi sırasında akromiyohumeral mesafedeki darlığın minimize edilebilmesinde humeral baş addüktör kas ko-aktivasyonunu potansiyel bir kompansasyon mekanizması olarak görmüşlerdir. ${ }^{19} \mathrm{Bu}$ düşünce üzerine planladıkları bir diğer EMG çalışmasında, istirahat pozisyonunda akromiohumeral mesafeyi ve aktif abdüksiyon ve addüksiyon hareketleri sırasında humeral translasyon miktarındaki farklılıkları değerlendirmişlerdir. ${ }^{19}$ RM yırtığı olan 20 hasta, subakromiyal sıkışması olan 30 hasta ve 10 kişilik kontrol grubu olmak üzere toplam 60 hasta ile çalışmalarını planlamışlardır. Tüm katılımcıların deltoid, pektoralis majör, latissimus dorsi ve teres majör aktivasyonları ilgili hareketler sırasında EMG ile kayıt altına alınmıştır. ${ }^{19}$ Subakromiyal aralığın RM yırtığı olan hastalarda, diğer bireylere göre daha dar olduğunu ifade etmişlerdir. ${ }^{19}$ Tüm deneklerde izometrik abdüksiyon sırasinda ve daha az miktarda adduksiyon sırasında subakromiyal daralmada artış ve ayrıca RM yırtığı olan hastalarda daha fazla addüktör kas ko-aktivasyonu saptamışlardır. ${ }^{19}$ Erken dönemde ko-aktivasyon artışının olması, RM kaslarındaki yetersizliğin kompanse edilmesinde önemlidir. ${ }^{20} \mathrm{Hu}$ meral baş depresör kas ko-aktivasyon eğitiminin olumlu etkileri ile ilgili sonuçlarımız, ko-aktivasyon miktarının artırılmasıyla RM kaslarının daha hızlı iyileşmesine olanak tanınmasıyla açıklanabilir. Klinikteki eğitimler sırasında rekürrent aktivite vasıtasıyla iyileşmenin hızlanması, 
ko-aktivasyon miktarını zamanla düşürecektir. ${ }^{21}$ Yırtık olan RM kasları iyileştikçe ko-aktivasyon azalması, gereksiz kassal aktivitenin ilerleyen inhibisyonunu sağlayacak ve çalışma sonuçlarımızda olduğu gibi daha iyi fonksiyonel skorlar elde edilebilecektir. ${ }^{21} \mathrm{Bu}$ bağlamda Witte ve arkadaşlarının bahsedilen 2 biyomekaniksel çalışması, sonuçlarımızın geçerliliğini desteklemesi açısından önemlidir., ${ }^{9}$

Humeral baş depresör kas ko-aktivasyon artışının etkilerini inceleyen bir diğer çalışma Overbeek ve arkadaşlarına aittir. ${ }^{18}$ Abduksiyon hareketi sırasında kol addüktör kas ko-aktivasyonunun artırılmasının subakromiyal ağrı sendromunun (SAPS) tedavisinde etkili olabileceği düşüncesiyle çalışmalarını planlamışlardır. ${ }^{18}$ İlk değerlendirmede ve yaklaşık 4 yıllık takipten sonra, SAPS' 1126 hastada izometrik abdüksiyon ve addüksiyon görevleri sırasında latissimus dorsi, teres major, pektoralis majör ve deltoid kasının EMG ölçümlerini kaydetmişlerdir. Klinik seyir VAS ile takip edilmiştir. Çalışma sonuçlarına göre latissimus dorsi ve teres majör kaslarının ko-aktivasyon artışı, olumlu bir SAPS seyri ile ilişkilidir. Semptomlardaki iyileşmeyi ise addüktör kas ko-aktivasyonunun artmasıyla subakromiyal mesafenin genişlemesiyle açıklamışlardır. ${ }^{18}$

Çalışmamızın limitasyonu yaş ile ilgilidir. Hastaların yaş dekatlarının gruplanarak skorların analiz edilmesi, sonuçların daha objektif ve genellenebilir olması açısından önemli olabilir. Sonuç olarak humeral baş depresör kas ko-aktivasyon eğitiminin konservatif tedavi programına eklenmesinin; istirahat, aktivite, Neer ve Kennedy-Hawkins olmak üzere 4 farklı pozisyonda ağrının azaltılmasına olumlu etkisi vardır. İnternal rotasyon hareketi dışında fleksiyon, abduksiyon ve eksternal rotasyon eklem hareket açıklı̆ının artırılmasında olumlu etkisi vardır.

Çalışmamız, Selçuk Üniversitesi Sağlık Bilimleri Fakültesi Girişimsel Olmayan Klinik Araştırmalar Etik Kurulu tarafından onaylandı (2020-622). Çalışma öncesi tüm bireylerin yazılı ve sözlü onamları alındı ve ayrıca çalışma Helsinki Bildirgesi’ne uyumlu şekilde gerçekleştirildi. 
Sakarya Tip Dergisi 2021;11(1):42-52

KARARTI ve Ark., Humeral Baş Depresör Kas Ko-Aktivasyon Eğitimi

\section{Kaynaklar}

1. Andersson HI, Ejlertsson G, Leden I, Rosenberg C. Chronic pain in a geographically defined general population: studies of differences in age, gender, social class, and pain localization. Clin J Pain 1993;9:174-182.

2. Steenbrink F, de Groot JH, Veeger HE, van der Helm FC, Rozin PM. Glenohumeral stability in simulated rotator cuff tears. J Biomech 2009;42:1740-1745.

3. de Witte PB, Overbeek CL, Navas A, Nagels J, Reijnierse M, Nelissen RG. Heterogeneous MR arthrography findings in patients with subacromial impingement syndrome - Diagnostic subgroups? J Electromyogr Kinesiol 2016;29:64-73.

4. Deutsch A, Altchek DW, Schwartz E, Otis JC, Warren RF. Radiologic measurement of superior displacement of the humeral head in the impingement syndrome. J Shoulder Elbow Surg 1996;5:186-193.

5. Graichen H, Bonel H, Stammberger T, Haubner M, Rohrer H, Englmeier KH, Reiser M, Eckstein $F$. Three-dimensional analysis of the width of the subacromial space in healthy subjects and patients with impingement syndrome. AJR Am J Roentgenol 1999;172:1081-1086.

6. Overbeek CL, Kolk A, de Groot JH, et al. Altered Cocontraction Patterns of Humeral Head Depressors in Patients with Subacromial Pain Syndrome: A Cross-sectional Electromyography Analysis. Clin Orthop Relat Res 2019;477(8):1862-1868.

7. Hinterwimmer S, Eisenhart-Rothe R, Siebert M, Putz R, Eckstein F, Vogl, T. Influence of adducting and abducting muscle forces on the subacromial space width. Med Sci Sport Exer 2003;35:2055-2059.

8. Steenbrink F, de Groot JH, Veeger HE, Meskers CG, van de Sande MA, Rozing PM. Pathological muscle activation patterns in patients with massive rotator cuff tears, with and without subacromial anaesthetics. Man Ther 2006;11:231-237.

9. de Witte $P B$, van der Zwaal $P$, Visch $W$, et al. Arm adductor with arm abduction in rotator cuff tear patients vs. healthy -- design of a new measuring instrument [corrected] [published correction appears in Hum Mov Sci 2013 Aug;32(4):875-6].

10. Boudreau N, Gaudreault N, Roy JS, Bédard S, Balg F. The Addition of Glenohumeral Adductor Coactivation to a Rotator Cuff Exercise Program for Rotator Cuff Tendinopathy: A Single-Blind Randomized Controlled Trial. J Orthop Sports Phys Ther 2019;49(3):126-135.
11. Kanık EA, Taşdelen B, Erdoğan S. Klinik denemelerde randomizasyon 2011.

12. Thigpen CA, Shaffer MA, Gaunt BW, Leggin BG, Williams GR, Wilcox RB 3rd. The American Society of Shoulder and Elbow Therapists' consensus statement on rehabilitation fol lowing arthroscopic rotator cuff repair. J Shoulder Elbow Surg 2016;25(4):521-535.

13. Price DD, McGrath PA, Rafii A, Buckingham B. The validation of visual analogue scales as ratio scale measures for chronic and experimental pain. Pain 1983;17(1):45-56.

14. Menek B, Tarakci D, Algun ZC. The effect of Mulligan mobilization on pain and life quality of patients with Rotator cuff syndrome: A randomized controlled trial. J Back Musculoskelet Rehabil 2019;32(1):171-178.

15. Hall MC. The Velpeau bandage. Can Med Assoc J 1963;88(2):92-93.

16. Juul-Kristensen B, Larsen CM, Eshoj H, et al. Positive effects of neuromuscular shoulder exercises with or without EMG-biofeedback, on pain and function in participants with subacromial pain syndrome - A randomised controlled trial. J Electromyogr Kinesiol 2019;48:161-168.

17. Yakut E, Dalkılınç M, Kaya D. Kantta dayalı elektroterapi. Ankara, Pelikan Yaytncllı 2008;43-203.

18. Overbeek CL, Kolk A, Nagels J. Increased co-contraction of arm adductors is associated with a favorable course in subacromial pain syndrome. J Shoulder Elbow Surg 2018;27(11):19251931.

19. de Witte PB, Henseler JF, van Zwet EW, Nagels J, Nelissen RG, de Groot JH. Cranial humerus translation, deltoid activation, adductor co-activation and rotator cuff disease - different patterns in rotator cuff tears, subacromial impingement and controls. Clin Biomech (Bristol, Avon) 2014;29(1):26-32.

20. Busse ME, Wiles CM, Van Deursen RWM. Muscle co-activation in neurological conditions. Physical therapy reviews 2005;10(4):247-253.

21. Andrade R, Araújo RC, Tucci HT, Martins J, Oliveira AS. Coactivation of the shoulder and arm muscles during closed kinetic chain exercises on an unstable surface. Singapore Med J 2011;52(1):35-41. 